\title{
A RACIAL PECULIARITY IN THE POLE OF THE TEMPORAL LOBE OF THE NEGRO BRAIN
}

\author{
ROBERT BENNETT BEAN
}

From the Anatomical Laboratory, the Tulane University of Louisiana

NINETEEN FIGURES (THREe PLATES)

While at the University of Michigan in 1906, I examined some casts of the interior of skulls which I had made in the Anatomical Laboratory of the Johns Hopkins University. My attention was struck by the apparently small size of the pole of the temporal lobe of the negro brain as compared with that of the white; and, proceeding to apply the calipers, the difference was demonstrated to be a measurable quantity. I then measured some brains from whites in the Anatomical Laboratory of the University of Michigan and others from both whites and negroes in the Anatomical Laboratory of the Johns Hopkins University, and at The Wistar Institute. I wish to thank Dr. McMurrich, Dr. Mall and Dr. Greenman for permission to use the material in their charge and for assistance in the work of making measurements.

\section{MATERIAL AND METHODS}

The material studied consisted of 127 brains of negro males, 53 of negro females and 53 of white males (no white females) and measurements were made on each temporal lobe in two planes. The two planes selected are called basal and pole. For the basal plane I selected a plane passing horizontally through the temporal lobe, beginning posteriorly on the inferior surface at a point where a shallow depression is found in the inferior lateral border of the lobe by the upward projection of the petrous portion of the temporal bone, and ending anteriorly at a line where, if the plane were extended, it would leave the temporal 
lobe to pass along the lowest part of the orbital surface of the frontal lobe. A straight-edged ruler laid alongside the brain will indicate the plane, if the edge of the ruler is on a level with the lower border of the frontal lobe and the depression in the temporal lobe made by the petrous bone.

The other or pole plane selected was parallel to the first and through a point $5 \mathrm{~mm}$. vertically above the lowest projecting point of the temporal lobe. The two planes were measured both in their antero-posterior and transverse diameters.

The planes selected are not always the same in the brains examined, but they are the best that could be located and the results bear out the evidences of inspection of brains, and of skull casts, as well as of photographs of these and the evidences of Hrdlička's measurements of the skull. Therefore they are dependable if only as an approximation of the condition. The measurements cover only a small part of the temporal lobe, and that the mere extremity.

It may be added that in calculating the standard deviation, skewness of the curve and probable errors, Pearson's methods or Davenport's formulae have been followed. The median has been used instead of the mean because of the small number of individual measurements, the ease of calculation and the almost exact identity of the two.

\section{MEASUREMENTS IN THE BASAL PLANF.}

The antero-posterior diameter of the basal plane shows the white males congregated about 52 to $56 \mathrm{~mm}$., the negro males about 50 to $54 \mathrm{~mm}$., and the negro females about 48 to $52 \mathrm{~mm}$. The mean, that is to say the point midway between the most extreme cases, is $54 \mathrm{~mm}$. for the whites, $52 \mathrm{~mm}$. for the negro males and $48 \mathrm{~mm}$. for the negro females. The median, that is to say the point with an equal number of cases on either side, is $54.3 \mathrm{~mm}$. for the white males, $51.5 \mathrm{~mm}$. for the negro males and $49.25 \mathrm{~mm}$. for the negro females, while the extremes are separated by $26 \mathrm{~mm}$. in the white males and in the negro males, but by only $22 \mathrm{~mm}$. in the negro females. The averages of the antero-posterior diameter of the basal plane of the three 
groups are $54.7 \mathrm{~mm}$. for the white males. $51.8 \mathrm{~mm}$. for the negro males and $49.4 \mathrm{~mm}$. for the negro females and the mode is $\mathbf{5 5}$ $\mathrm{mm}$. for the white males, $52 \mathrm{~mm}$. for the negro males and 50 $\mathrm{mm}$. for the negro females.

From these figures it will be seen that the antero-posterior diameter of the basal plane of the temporal lobe is greater in the white males than in the negro males and greater in the negro males than in the negro females, in the mean, on the average and by the median and the mode, the difference being about $3 \mathrm{~mm}$. between the white males and the negro males and about $2 \mathrm{~mm}$. between the negro males and females.

Hrdlička has measured the antero-posterior diameters of the fossae of the skull in various races, both in adult individuals and young, and in monkeys and other animals, and has determined that the temporal or middle fossa of the negro skull is absolutely shorter than that of the white or that of the Indian, and that it is also shorter in proportion to the total external length of the skull, this being especially noticeable in dolichocephals. His results are based on measurements of 55 negro skulls, male and female, compared with those of 90 white skulls, male and female, and those of the skulls of 20 Indian males. Although the points and planes selected are not exactly the same as those I used, yet there is no very great difference between his and mine, and the results of the two sets of measurements, the one on the skull and the other on the brain, are corroborative.

As regards the transverse diameter of the basal plane, the white males are grouped around 48 to $50 \mathrm{~mm}$., the black males around 42 to 46 and the black females around 44 to 46 . The mean is $49 \mathrm{~mm}$. for the white male, $42 \mathrm{~mm}$. for the negro male and $44 \mathrm{~mm}$. for the negro female, and the median is 49 for the white male and 44 for both the male and female negro. The extremes are separated by $14 \mathrm{~mm}$. in the white male, by $22 \mathrm{~mm}$. in the black male and by $18 \mathrm{~mm}$. in the black female. The averages are $49.3 \mathrm{~mm}$. for the white male, $44.4 \mathrm{~mm}$. for the negro male and $44.5 \mathrm{~mm}$. for the negro female; and the mode is $50 \mathrm{~mm}$. for the white male, $46 \mathrm{~mm}$. for the negro male and 44 $\mathrm{mm}$. for the negro female. 
The transverse diameter of the temporal lobe in the basal plane is accordingly greater in the white male than in the negro male by about $5 \mathrm{~mm}$. and it is about the same size in the two sexes of the negro, in the mean and in the average, by the median and by the mode. A comparison will show that there is a greater racial difference between the two sets of males in this, the transverse, diameter of the basal plane than in the antero-posterior one. Taking the averages, the difference between the two diameters in the white male brain is 54.7 minus 49.3 equals $5.4 \mathrm{~mm}$., while that in the negro male brain is 51.8 minus 44.4 equals $7.4 \mathrm{~mm}$., the transverse diameter of the basal plane as compared with the antero-posterior diameter being thus $2 \mathrm{~mm}$. less in the negro male than in the white male, or, conversely, the anteroposterior diameter relatively to the transverse is $2 \mathrm{~mm}$. greater in the negro male than in the white male. This difference may, perhaps, be better expressed by representing the relation by an antero-posterior transverse index in which the transverse diameter is taken as 100 . Then the index for the male white is 110.9 , while that for the male negro is 116.4. The difference between the averages of the diameters in the negro female is $4.9 \mathrm{~mm}$., differing from that of the white male by $0.5 \mathrm{rm}$., while the index is 111, almost identical with that of the white male.

Hrdlička has measured the pituitary fossa in negro and white skulls, but his measurements do not extend to the body of the sphenoid bone and hence cannot be used for comparison.

\section{MEASUREMENTS OF THE POLE PLANE}

The measurements made at $5 \mathrm{~mm}$. from the lowest projecting point of the temporal lobe are necessarily less accurate than those of the other two planes on account of the greater difficulty of obtaining the exact location of the plane, the variable shape of the temporal pole, etc. There is, however, an appreciable racial difference. The modes of the white males are about $26 \mathrm{~mm}$. and about $34 \mathrm{~mm}$.; those of the black males about $22 \mathrm{~mm}$. and about $28 \mathrm{~mm}$; and those of the black females about $16 \mathrm{~mm}$., about $20 \mathrm{~mm}$. and about $26 \mathrm{~mm}$. This multiple grouping is 
due to the different shapes of the temporal pole, some being long, others round, while others are oval or oblong. These various shapes occur in each race-sex group and hence do not interfere with a fair comparison.

The transverse diameter of the pole plane is more homogeneous than the antero-posterior. The white males are grouped about $24 \mathrm{~mm}$. and the negro males and females about $18 \mathrm{~mm}$. The numbers of about the same value are more extensive than in the other arrays, indicating a tendency to a large grouping about the mode. A curve to illustrate this would be platycurtic, or flat-topped (McDonnell). The transverse diameter of the pole plane passes below the hippocampus.

THE SIZE OF THE TEMPORAL LOBE RELATIVE TO THE BRAIN WEIGHT AND SIZE

A comparison of the size of the temporal lobes with the total brain weights was made in the brains of 34 negro males, 21 negro females and 13 white males, and the results showed that there was a slight increase in the size of the temporal lobe with increase of brain weight, and that this increase was greatest in the white males and greater in the negro female than in the male. The brain weight of the white is greater than that of the negro and this might possibly account for the difference in the size of the temporal lobes as already determined. But this indicates that the lobes of the white are larger absolutely and relatively to brain weight, than those of the negro.

The same result is obtained by a comparison of the diameters of the temporal lobes with the diameters of the cerebral hemispheres to which they belong, length with length and breadth with breadth.

It will be seen that both in series and by averages the white has the advantage of the negro, the dimensions of the temporal lobes are actually greater in the white except in the case of the antero-posterior diameter of the basal plane, where the negro female has an advantage of $1 \mathrm{~mm}$. in the average over the white male and of $2.6 \mathrm{~mm}$. over the negro male. 


\section{CONCLUSIONS}

The general conclusions may be stated concisely as follows:

1. The size of the pole of the temporal lobe is less in the negro than in the white, and less in the negro female than in the male.

2. The differences are more pronounced in measurements taken below the hippocampus than in those which pass through that structure. Hence it is probable that

3. The hippocampus is larger in the negro than in the white and larger in the negro female than in the male.

4. The shape of the pole of the temporal lobe is different in the two races, being slightly more slender in the negro, and almost the same size in the two races antero-posteriorly

5 . The differences are not only absolute but are also relative to the weight and size of the entire cerebral hemispheres.

The brains collected at Tulane University confirm the evidence in relation to the temporal lobe of the brains examined at the University of Michigan, at The Wistar Institute, and at the Johns Hopkins University. The brains examined at Tulane University were preserved in a uniform manner, but the brains examined in the other places were not, and the differences noted at Tulane University are more distinct than elsewhere.

NOTE CONCERNING RECENT OBSERVATIONS ON THE NEGRO BRAIN

The brains examined here were preserved in the following manner: The bodies from which the brains were removed were injected with the usual Souchon solution as soon after death as possible, usually at least twenty-four hours after, and they were allowed to remain another twenty-four hours before the brains were removed. The skull caps were sawed as low down over the forehead and occipital region as practicable to remove the cap without disturbing the brain, and after the removal of the brain it was weighed and placed in 10 per cent formalin solution, base up, fitting it into the skull cap. The brains were found to harden readily, and to retain their shape especially well in the region of the temporal lobes. The skull cap being the shape of the vertex this also retains its shape. Should the brain be soft it may spread a little over the cut sides of the skull cap, 
but if the brains are fitted well into the skull cap this seldom occurs.

In a test of the accuracy of my powers of observation, nine brains were selected at random without knowing their race character, and from the temporal lobes alone I judged the race correctly in all except two, which I called white, whereas they were from light-skinned mulattoes.

The brains have been measured in various dimensions, and observations as to the size of the pons, cerebellum, convolutions, etc., have been made, but these are reserved for future publication.

The temporal lobe of the brain may be described better than it can be measured. The upper part of the lateral side of the lobe in the negro brain is flat and the lateral side is also flat as it turns downward, inward and forward straight to the tip or pole of the lobe. In the white brain the upper part of the lateral side of the lobe is round, and the lateral side is also round and instead of passing downward as a flat surface it makes a graceful rounded sweep inward to the pole of the lobe.

The medial surface of the temporal lobe is almost perpendicular in the white brain, but in the negro it slopes outward. This makes the temporal lobe of the white brain appear to turn inward at the pole, whereas in the negro brain it is directed downward.

The pole of the temporal lobe is more slender, smaller and narrower in the negro than in the white brain.

The temporal pole of the brain of the negro female is more like that of the white than is the brain of the negro male, especially on the lateral surface, and this is due to the rounded surface of the female negro brain and the angular surface of the male negro brain.

\section{LITERATURE CITED}

BEAN, R. B. 1906 Some racial peculiarities of the negro brain. Am. Jour. Anat., vol. 5 .

DAVEnPoRT, C. B. 1904 Statistical methods.

HrDLČ̌Ka, A. 1899 Dimensions of the normal pituitary fossa or sella turcica in the white and negro races. Archives Neurol. and Psychol. Path. 1907 Measurements of the cranial fossae. Proc. U. S. Natl. Museum, vol. 32 .

MCDonnel.L, W. R. 1904 Variation and correlation of the human skull. Biometrica, 3. 


\section{PLATTE 1}

\section{EXPLANATION OF FIGURES}

1 Skull casts; side view. Note the narrow pole of the temporal lobe in the negro skull cast.

$\begin{array}{ccccc}\text { White male } & \text { White male } & \text { White male } & \text { Negromale } & \text { Negromale } \\ 1245 & 1245 & 1216 & 1582 & 1582 \\ \text { Dura } & \text { Dura } & \text { No dura } & \text { Dura } & \text { Dura }\end{array}$

The numbers refer to the serial number of brains (subjects) at the Johns Hopkins Anatomical Laboratory.

2 Skull casts; view from below. Note the wide pole of the temporal lobe in the white skull cast; note also the great width of the space between the poles in the negro casts.

$\begin{array}{ccccc}\text { Negro male } & \text { Negro male } & \text { White male } & \text { Negro male } & \text { Negro male } \\ 1247 & 1330 & 1216 & 1212 & 1217 \\ \text { Dura } & \text { Dura } & \text { No dura } & \text { No dura } & \text { No dura }\end{array}$

3 Brains; view from below. Note the narrow poles of the temporal lobes of the negro brain and cast and the wide space between them.

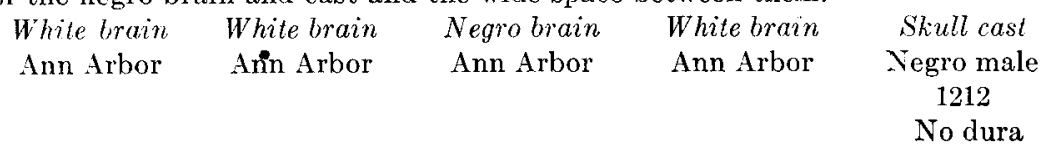

4 Skull casts; front view. Note the narrow temporal poles and the wide space between them in the negro skull casts.

$\begin{array}{ccccc}\text { Negro male } & \text { Negro male } & \text { White male } & \text { Negromale } & \text { Negromale } \\ 1219 & 1217 & 1216 & 1330 & 1247 \\ \text { Dura } & \text { No dura } & \text { No dura } & \text { Dura } & \text { Dura }\end{array}$



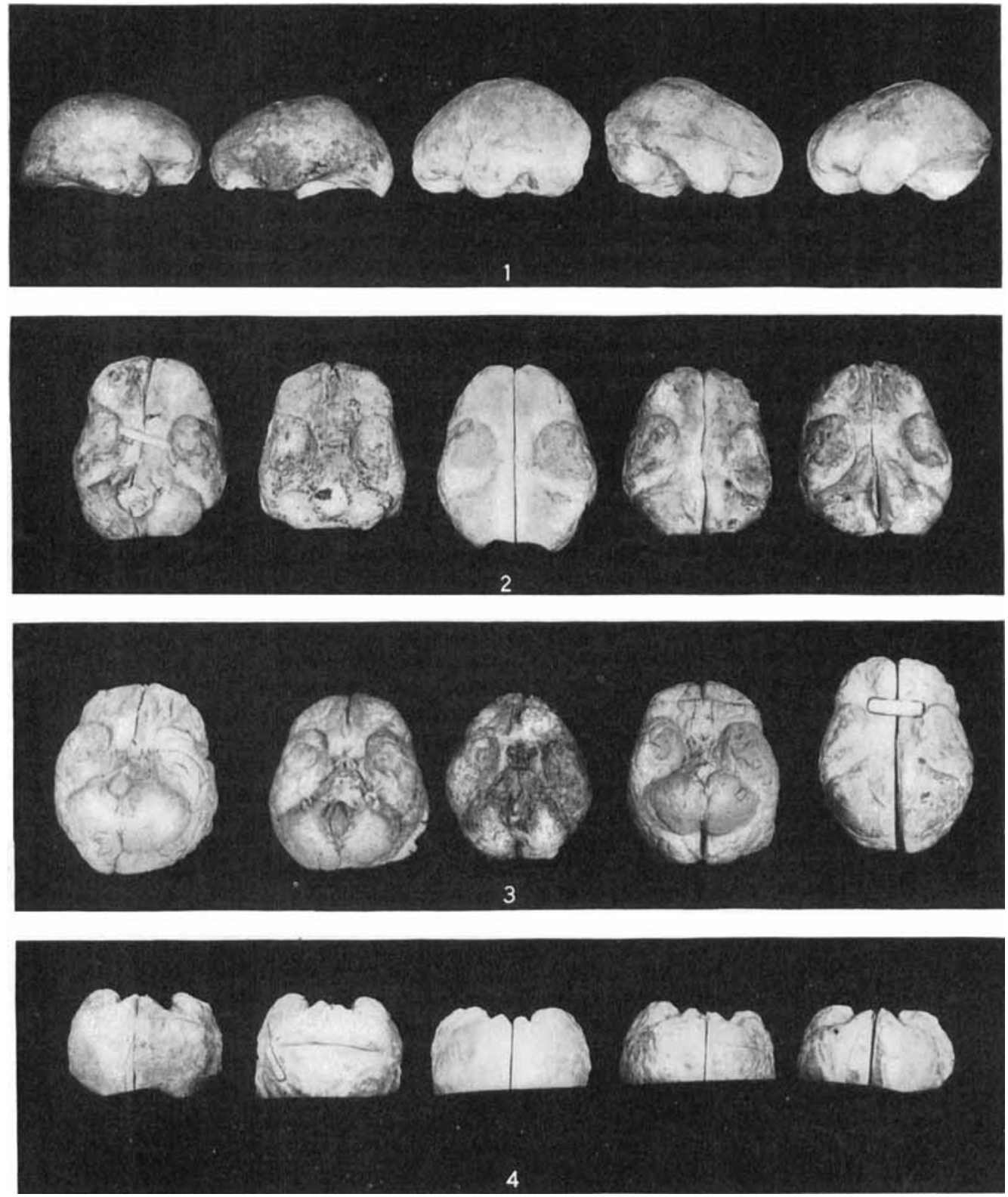


\section{PLATE 2}

\section{EXPLANATION OF FIGURES}

The outlines in figures 5 to 19 inclusive were made from projections through a lens with the brains each at the same focal distance from the lens. The gyri and sulei of the temporal lobes are given, as only these are in focus. The outlines show the temporal lobes as if viewed from above through transparent brain substance.

5 Brain 2; white male; age 25; cause of death, pulmonary tuberculosis. Total brain length, right hemisphere $16 \mathrm{~cm}$; left hemisphere $15 \mathrm{~cm}$; total brain breadth $14 \mathrm{~cm}$; total brain height $10.1 \mathrm{~cm}$. weigh 1304 grams. Note the wide temporal lobes.

6 Brain 1; negro male, age 65; cause of death, nephritis. Total brain length, right hemisphere $17 \mathrm{~cm}$; left hemisphere $17.2 \mathrm{~cm}$.; total brain breadth $14 \mathrm{~cm}$. Weight 1361 grams. Note the narrow temporal lobes.

7 Brain 6; white male; age 55; cause of death, pulmonary tuberculosis. Total brain length, right hemisphere $16.2 \mathrm{~cm}$.; left hemisphere $16.5 \mathrm{~cm}$.; total brain breadth $14 \mathrm{~cm}$.; total brain height $10.4 \mathrm{~cm}$. Weight 1332 grams. Note the wide temporal lobes.

8 Brain 8 ; negro male; age 48; cause of death, tuberculosis. Total brain length, right hemisphere $16.7 \mathrm{~cm}$; left hemisphere $16.8 \mathrm{~cm}$.; total brain breadth $13.6 \mathrm{~cm}$. Weight 1503 grams. Note the narrow temporal lobes.

9 Brain 7; negro female; age 75; cause of death, unknown. Total brain length, right hemisphere $16.1 \mathrm{~cm}$.; left hemisphere $16.1 \mathrm{~cm}$.; total brain breadth $12.4 \mathrm{~cm}$. Weight 992 grams. Note narrow tips of the temporal lobes.

10 Brain 10; white female; age 23; cause of death, lobar pneumonia. Total brain length, right hemisphere $15.5 \mathrm{~cm}$.; left hemisphere $15.7 \mathrm{~cm}$; total brain breadth $12.6 \mathrm{~cm}$; total brain height $10.6 \mathrm{~cm}$. Weight 1155 grams. Note the wide temporal lobes.

11 Brain 9 ; negro male; age 38 ; cause of death, pulmonary tuberculosis. Total brain length, right hemisphere $16.5 \mathrm{~cm}$; left hemisphere $16.4 \mathrm{~cm}$; total brain brearlth $13.5 \mathrm{~cm}$; t total brain height $10.6 \mathrm{~cm}$. Weight 1304 grams. Note the narrow poles of the temporal lobes.

12 Brain 3; mulatto male; age 53; cause of death, nephritis. Total brain

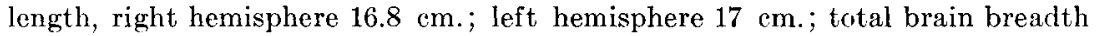
$13.6 \mathrm{~cm}$. Weight 1389 grams. Note the wide temporal lobes like those of the white, 

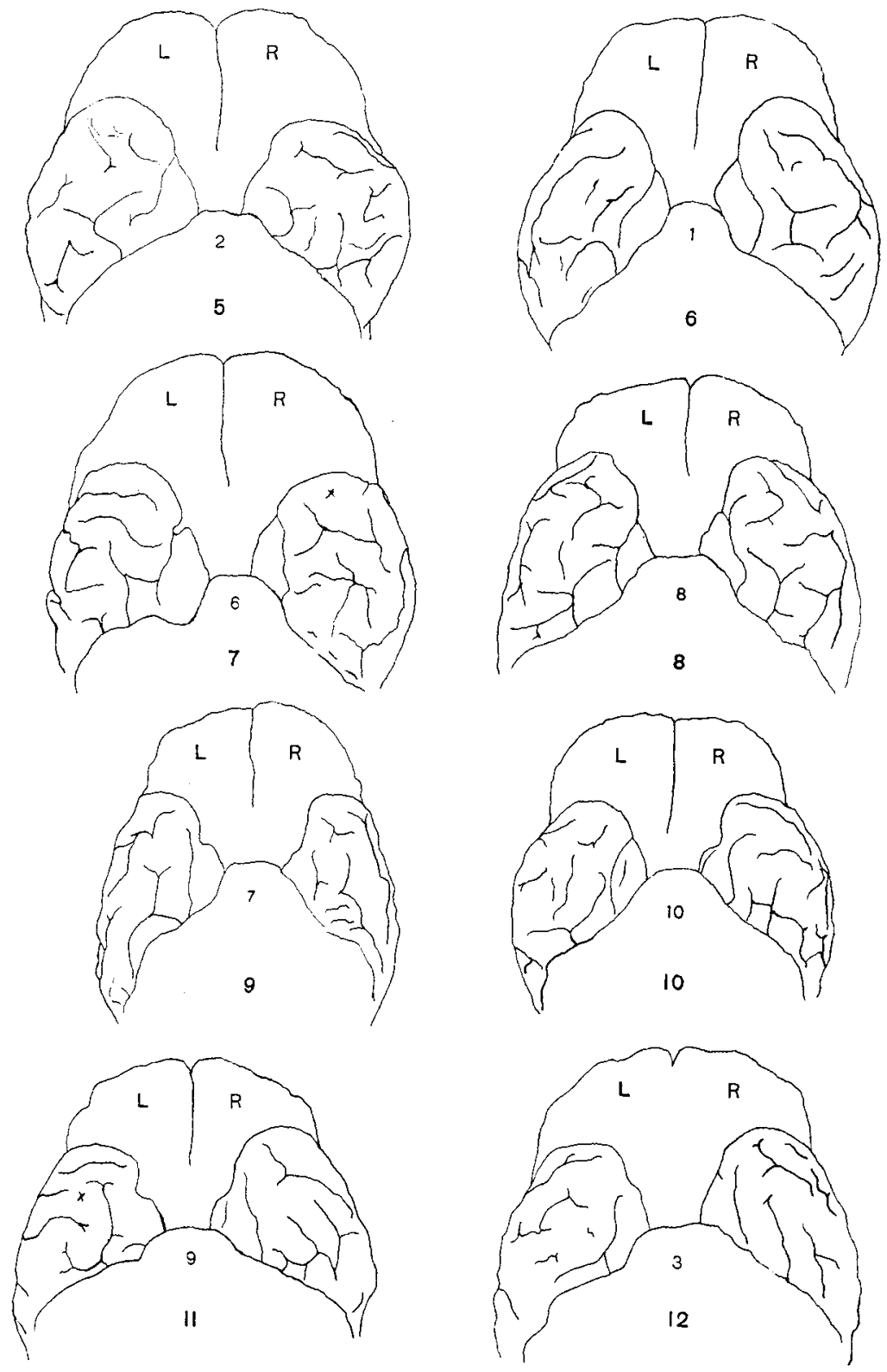
PLATE 3

EXPLANATION OF Figures

13 Brain 14; negro male; age 38; cause of death, pulmonary tuberculosis. Total brain length; right hemisphere $15.8 \mathrm{~cm}$.; left hemisphere $15.6 \mathrm{~cm}$.; total brain breadth $12.1 \mathrm{~cm}$; total brain height $9.9 \mathrm{~cm}$. Weight 1106 grams. Note the narrow temporal lobes.

14 Brain 4; negro male; age 65; cause of death, nephritis. Total brain length, right hemisphere $16.7 \mathrm{~cm}$.; left hemisphere $16.7 \mathrm{~cm}$; t total brain breadth $12.1 \mathrm{~cm}$. Weight 1219 grams. Note the narrow temporal lobes.

15 Brain 12; negro female, age 70; cause of death, arterio-sclerosis. Total brain length, right hemisphere $16.3 \mathrm{~cm}$.; left hemisphere $16.7 \mathrm{~cm}$. ; total brain breadth $12.3 \mathrm{~cm}$; total brain height $10.9 \mathrm{~cm}$. Weight 1169 grams. Note the narrow points of the temporal lobes.

16 Brain 11; mulatto female; age 24; cause of death, pulmonary and intestinal tuberculosis. Total brain length, right hemisphere $17 \mathrm{~cm}$. (distorted; left hemisphere $16.4 \mathrm{~cm}$; total brain breadth $12.8 \mathrm{~cm}$. Weight 1155 grams. The temporal lobes are as wide as in the white.

17 Brain 15; negro male; age 28; cause of death, lobar pneumonia. Total brain length, right hemisphere $17.1 \mathrm{~cm}$; ; left hemisphere $17.1 \mathrm{~cm}$; total brain breadth $12.7 \mathrm{~cm}$. Weight 1304 grams. Note the narrow point of the temporal lobes and the large hippocampus.

18 Brain 13; negro female; age 23; cause of death, pulmonary tuberculosis. Total brain length, right hemisphere $16.6 \mathrm{~cm}$.; left hemisphere $16.4 \mathrm{~cm}$.; total brain breadth $12.7 \mathrm{~cm}$. Weight 1219 grams. Note the narrow point of the temporal lobes and the large hippocampus.

19 Brain 5; mulatto male; age 39, cause of death, lobar pneumonia. Total brain length, right hemisphere $16.8 \mathrm{~cm}$; left hemisphere $16.8 \mathrm{~cm}$; total brain breadth $12 \mathrm{~cm}$. Weight 1233 grams. The temporal lobe is wide as in the white. 

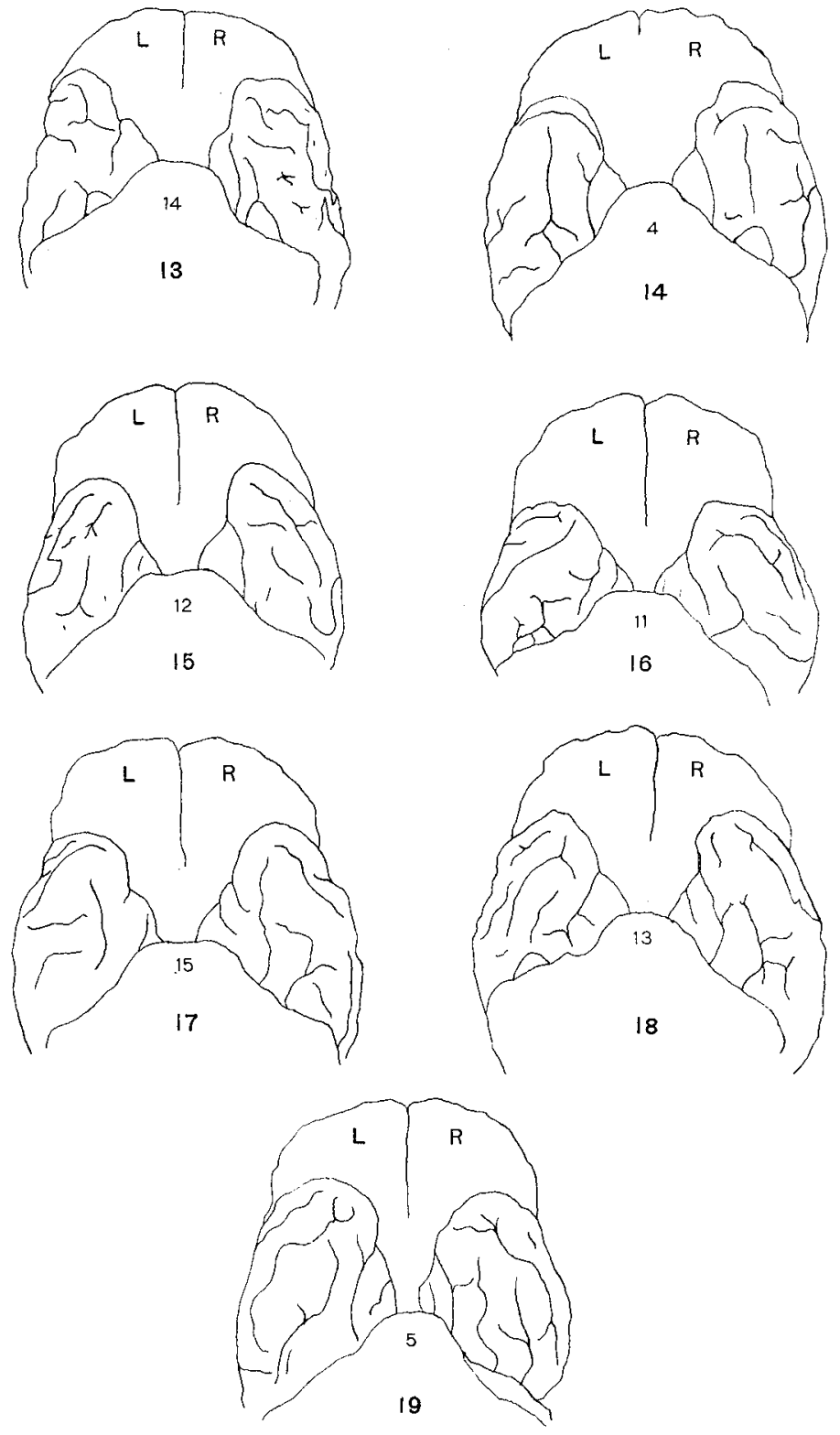